\title{
Atomic-Resolution Imaging of Heterogeneous Catalysts at Work
}

S. Helveg ${ }^{1}$, C. F. Elkjær ${ }^{1}$, S. P. Jespersen ${ }^{1}$, S. Vendelbo ${ }^{1}$, B. Hendriksen ${ }^{2}$, L. Mele ${ }^{2}$, P. Dona ${ }^{2}$, J. F. Creemer $^{3}$, P. Kooyman ${ }^{4}$, I. Chorkendorff ${ }^{5}$, C. Damsgaard ${ }^{5}$ and J. R. Jinschek ${ }^{6}$

${ }^{1}$. Haldor Topsoe A/S, Haldor Topsøes Allé 1, Kgs. Lyngby, Denmark.

2. Thermo Fisher Scientific, Achtseweg Noord 5, Eindhoven, The Netherlands.

3. DIMES-ECTM, Delft University of Technology, Delft, The Netherlands.

4. Department of Chemical Engineering, University of Cape Town, South Africa.

5. Department of Physics, Technical University of Denmark, Denmark.

6. Department of Materials Science and Engineering, Ohio State University, OH.

Transmission electron microscopy (TEM) has become indispensable in the study of heterogeneous catalysts. The ability to acquire atomic-resolution images of catalysts opens up for unprecedented new information about the catalyst surface that benefits the understanding of structure-sensitivity in catalysis [1]. However, surfaces of most materials tend to restructure in reactive gas environments and such changes have a profound feedback on catalysts' properties. It has therefore remained an important milestone in catalysis and surface sciences to functionalize electron microscopy for operando studies in which the catalyst surface structure and properties are simultaneously evaluated at the atomic-scale and under relevant reaction conditions.

Here, we report on a nanoreactor system that enables combined electron microscopy and functional measurements of catalysts [2-6] and is available from Thermo Fisher Scientific. The nanoreactor is a micro-electro-mechanical system device integrating a 5- $\mu \mathrm{m}$-high, one-pass and bypass-free gas-flow channel, a microheater and an array of 15-nm-thick electron-transparent windows of silicon nitride (Figure 1) [4]. This nanoreactor is operational with variable gas flows $(0-0.1 \mathrm{sccm} / \mathrm{min})$, ambient pressure levels $(>1 \mathrm{bar})$ and elevated temperatures $\left(25-700{ }^{\circ} \mathrm{C}\right)$, while maintaining the inherent $1 \AA$ resolution in modern electron microscopes. Moreover, mass spectrometry of gas exiting the reaction zone is made possible by the small reaction volume of ca. $0.3 \mathrm{~nL}$ and reaction calorimetry is accessed from the power compensation used for isothermal operation of the microheater [6].

The nanoreactor performance and application will be showcased by observations of Pt nanoparticles under oxidizing and reducing reaction conditions. Specifically, high-resolution TEM images were acquired of the Pt nanoparticles under exposure to reactive gas environments synchronously with mass spectrometry and calorimetry data. Based on such observations, structure-activity relationship will be outlined for e.g. the steady-state and oscillatory catalytic oxidation of carbon monoxide over Pt nanoparticles [6]. These examples demonstrate exciting possibilities for including information about the exposed surface sites into the description of dynamic properties and functions of catalysts. 
References:

[1] S. Helveg, J. Catal. 328 (2015), p. 102.

[2] J.F. Creemer et al, Ultramicroscopy 108 (2008), p 993.

[3] J.F. Creemer et al, J. Microelectromech. Syst. 19 (2010), p. 254.

[4] J.F. Creemer et al, Proceedings of MEMS 2011 (2011), p. 1103.

[5] S.B. Vendelbo et al, Ultramicroscopy 133 (2013), p. 72.

[6] S.B. Vendelbo et al, Nature Materials 13 (2014), p. 884.
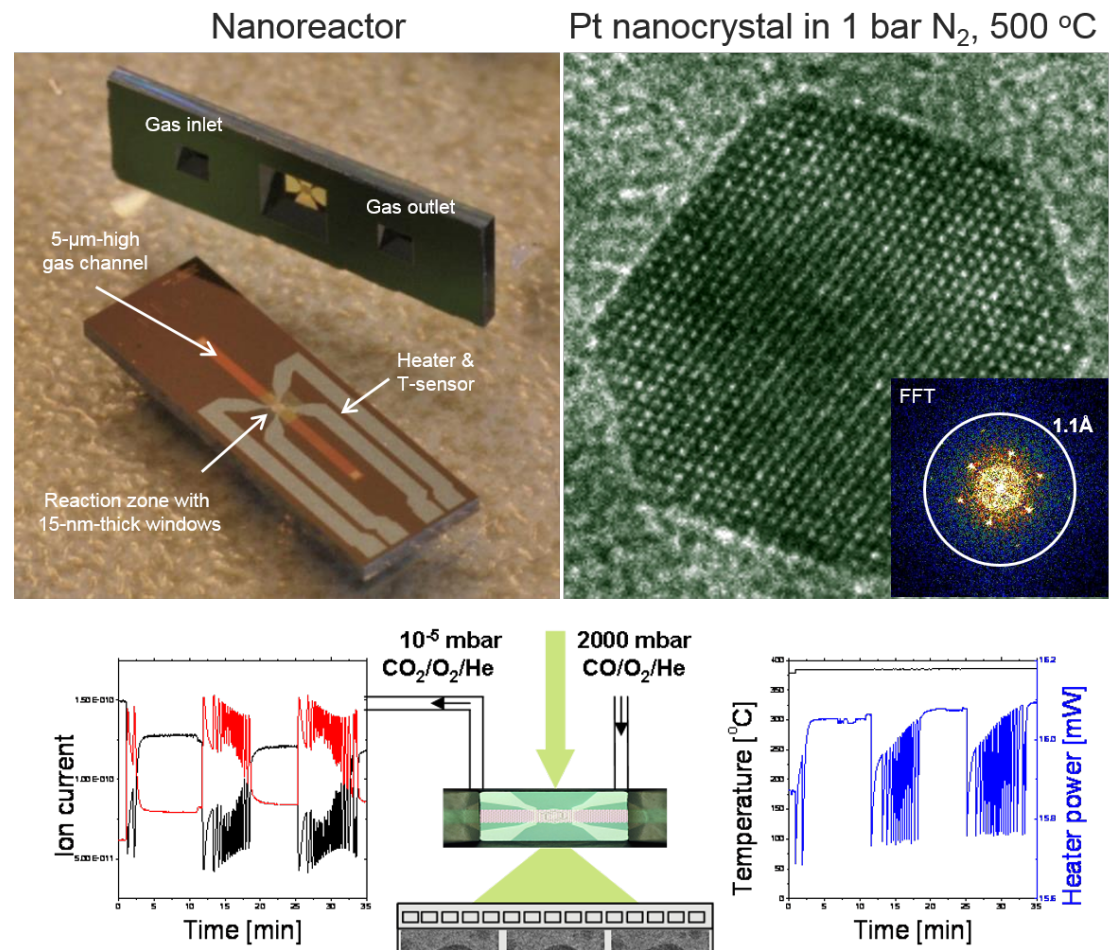

Mass spectrometry

$\sim \mathrm{O}(1-10 \mathrm{~s})$
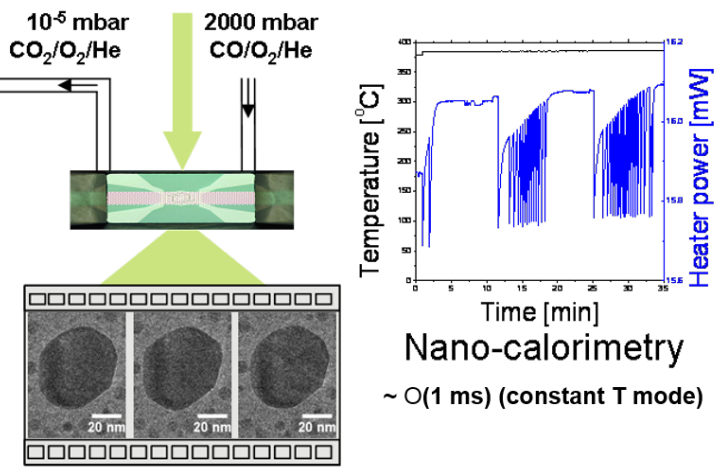

Nano-calorimetry

$\sim \mathrm{O}(1 \mathrm{~ms})$ (constant T mode)

Time resolved TEM

$\sim \mathrm{O}(0.1-1 \mathrm{~s})$

Figure 1. A nanoreactor concept enabling operando studies in catalysis. The nanoreactor is designed for atomic-resolution TEM observations of nanomaterials under exposure to gaseous reaction conditions at ambient pressure levels and enables synchronous electron microscopy, mass spectrometry and reaction calorimetry observations. Adapted from $[4,6]$. 